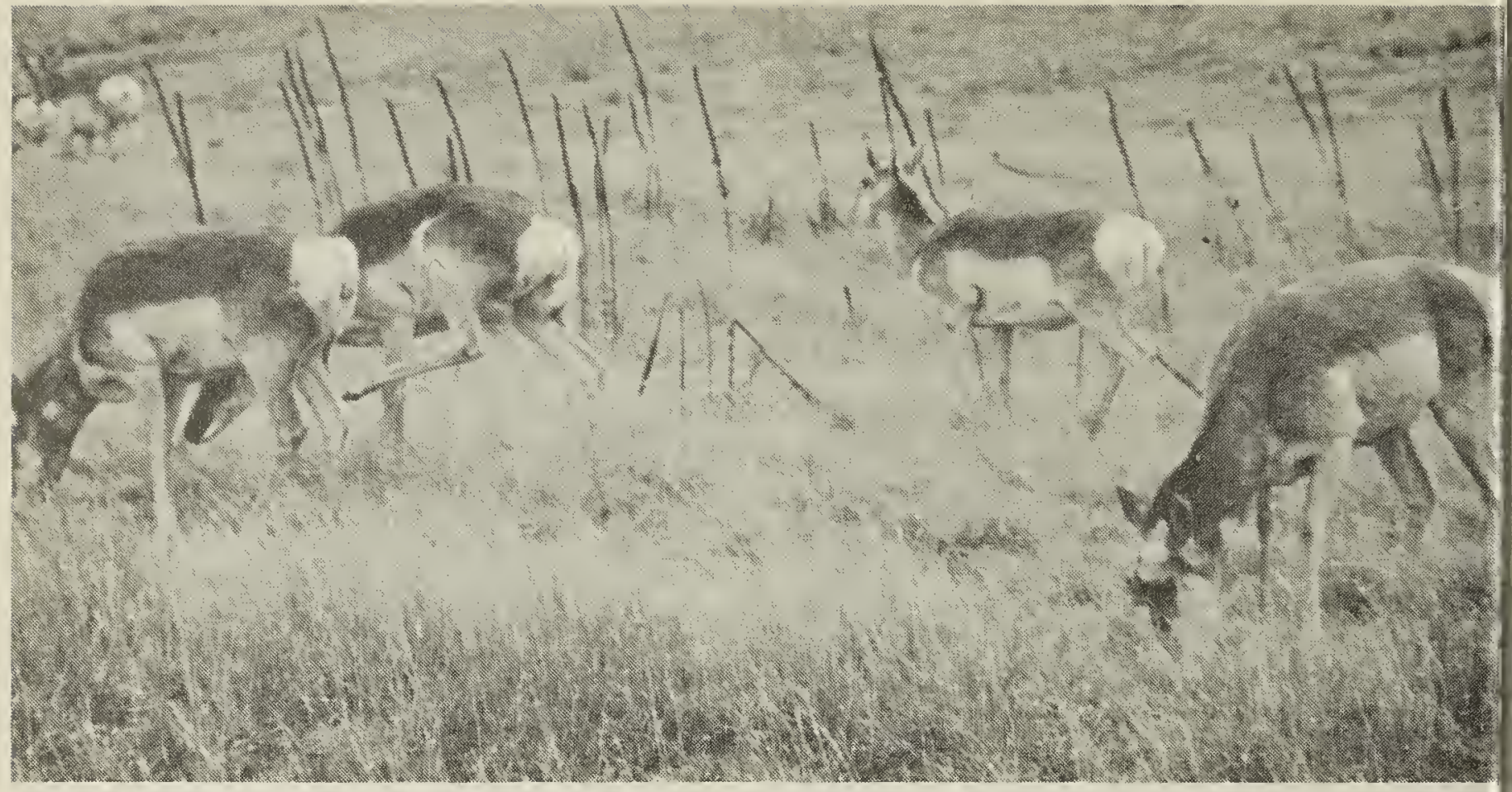

Pronghorns

Lorne Sco

\title{
PARKS CANADA COMMENTS
}

The following is the text of a letter dated July 10,1975 , from G. M. Davison of Parks Canada, 114 Garry St., Winnipeg, to Maureen Rever:

I read your paper on "A Grasslands Park - Yes or No" with a great deal of interest. The concerns expressed by you are relevant and are concerns of a large number of Canadians. We are also concerned with these matters and we hope that the following approach will give many people the opportunity of making their views known to us and to the Saskatchewan Government.

Parks Canada and the Saskatchewan Government are now in the process of drafting an information booklet for the Grasslands hearings, which will be sent out to interested groups and to people in the immediate area of the proposed Park. This booklet will be distributed around mid-August, thus giving the general public a chance to evaluate the contents prior to any public meetings.

On or about September 15th, the Saskatchewan Government and Parks Canada will commence holding a series of information-type meetings at various locations in the Province of Saskatchewan. These meetings are to be held with the intent to clarify ar misunderstandings that may develo as people evaluate the contents of th booklet.

The information-type meetings wi be followed by public hearings whic will commence in late fall. Again the meetings will be held in variou locations in the Province of Saska chewan, thus giving all intereste groups and individuals an opportuni to make their views known.

Your comments on biased info mation were well taken and to avo this pitfall we will be trying to prese all information as straightforward possible. In addition to this, an $\mathrm{i}$ dependent chairman will be appointe for the public hearings, theret reducing the chance of biased opinio from influencing any final decisions

The commission of enquiry will submitting their report to the $t v$ ministers sometime in December early January which will outline $t$ degree of support for the propos Park. Afterwards the Saskatchew Government will be in a position make a decision on the proposal. Yours sincerely, G. M. Davison, $f$ Director. 